\title{
Reproductive Performance of Koekoek Chickens at Different Levels of Feed Restrictions
}

\author{
Setsumi Motsoene Molapo ${ }^{1}$, Edward Webb ${ }^{2}$, Motselisi Aloycia Mahlehla ${ }^{1}$, Thato Chabeli ${ }^{1}$, and Paseka Kompi ${ }^{1}$ \\ ${ }^{1}$ Department of Animal Science, National University of Lesotho, P.O. Roma 180, Lesotho \\ ${ }^{2}$ Department of Animal and Wildlife Sciences, University of Pretoria, Pretoria 0002, South Africa \\ *Corresponding author's Email: setsomimolapo@ gmail.com, ORCID: 0000-0002-4426-8901
}

Received: 07 Oct. 2020

Accepted: 18 Dec. 2020

\begin{abstract}
The objective of the present study was to determine the impact of the feeding levels on the reproductive characteristics of Koekoek chickens. A total of 270 Koekoek chickens were randomly assigned to 4 feeding level treatments in a completely randomized design. The four feeding level treatments were fully fed during the rearing and laying phase (AA), fully fed during the rearing phase and restricted feeding during the laying phase (AR), restricted feeding during the rearing phase and fully fed during the laying phase (RA), and restricted both during the rearing and laying phase (RR). The General Linear Model procedure (SPSS software, version 17) was used to analyze the data set. The pubic bone measurements were 23.6, 25.1, 16.1, and $15.1 \mathrm{~mm}$ for chickens that received AA, AR, RA, and RR treatments, respectively, at 18 weeks of age. At 32 weeks of age, chickens given AA and RA treatments had wider pubic bones than chickens given AR and RR treatments. Combined ova and oviduct weights were higher in the fully fed chickens at 18 weeks of age. Koekoek chickens in AA treatment had the highest average egg production. Chickens given AR treatment had lower average egg weights than those given AA, AR, and RR treatments. Chickens treated with AA and AR reached puberty earlier than those that were treated with the RA and RR treatments. The eggs produced by chickens given RR treatment had a higher average hatching percentage. The lowest percentage of hatches was observed in chickens that were fed ad libitum during the rearing phase. In conclusion, the feed restriction only during the rearing phase improved the reproduction performance of Koekoek chickens.
\end{abstract}

Keywords: Egg weight, Fully fed, Hatchability, Koekoek, Laying percentage, Oviduct, Pubic bone, Restricted

\section{INTRODUCTION}

Feeding is one of the greatest determinants required for higher egg production. The high costs of chicken feed are making it impossible for the poor resource farmers in rural areas of Lesotho to keep laying chickens. One of the strategies to reduce high feeding costs is to use restricted feeding. Salih et al. (2016) believed that periodic restriction of the daily feed to simulate compensatory growth was a means of reducing feed cost. Feed restriction was used to control the development of chickens in order to reduce the incidence of metabolic diseases and enhance feed efficiency (Trocino et al., 2020). In addition, Adegbenro et al. (2020) indicated that feed restriction was the strategy aimed at reducing the growth and metabolic rate and hence the delay in sexual maturity of chickens during the growing phase. This consequently increased body weight and production without negatively impacting welfare and health. Moreover, Simeneh (2019) confirmed that unrestricted feeding of laying hens led to waste of energy, which promoted the unnecessary build-up of abdominal fat and predisposed layers to heat stress.

Yildiz et al. (2006) considered feed restriction as a strategy to reduce oviduct development. Crounch et al. (2002) also reported that feed restriction during the rearing phase could result in heavier mature ova. The higher hatchability was recorded in the treatment with restricted feed in a study on turkeys (Crounch et al., 2002). However, Melnychuk et al. (2004) reported heavy oviducts in chickens that were fed ad libitum. Crounch et al. (2002) also found similar results although the study was performed on turkeys. Regarding ovary development, some studies indicated a greater weight in the ad libitum fed chickens (Melnychuk et al., 2004; Renema et al., 1999). On the other hand, the obtained results of a study performed by Evrim and Kaya (2014) showed similar laying production between quails fed differently prior to sexual maturity. In a study conducted on quails, it was indicated that fertility and hatchability were not affected by the feeding regime (Evrim and Kaya, 2014). 
Since the Koekoek chickens were introduced in Lesotho, insufficient or no scientific studies have been conducted on their feeding management. Therefore, it is important to determine the feeding level that aims to maximize egg production and hatchability at affordable feed costs. The present study was, therefore, carried out to investigate the effect of restricted feeding on the laying and hatching performance of Koekoek chickens.

\section{MATERIALS AND METHODS}

\section{Ethical approval}

The Research and Ethics Committee in the Department of Animal Science at the National University of Lesotho approved this study based on international animal welfare standards for the use of animals in conducting research.

\section{Animals management and experimental design}

The present study was carried out at the National University of Lesotho situated in Roma, Lesotho, an experimental farm of the Faculty of Agriculture. Chickens were bought and fed commercial feeds at eight weeks of age. Upon arrival, they were given a stresspack (water soluble vitamin and electrolyte supplement) to reduce travel stress, which could lead to death. Chickens were reared under the deep litter system. Each pen was equipped with three wooden nests measuring $40 \times 40 \times 40$ $\mathrm{cm}$. From 8 to 18 weeks chickens ate pullet grower, then from 19 to 32 weeks, they were fed laying mash bought from the local commercial feed manufacturer. Chickens were given water without restriction. A completely randomized design of four feeding level treatments was used. The four feeding level treatments were AA, AR, RA, and RR. Each treatment had 10 hens and one rooster. Each treatment was replicated 7 times, except for the RR treatment, which was replicated 6 times, which means there were 270 hens and 27 roosters. At day 130 and 32 weeks (224 days) of age, 7 Koekoek hens per treatment were killed by cervical dislocation. The chickens were starved for 24 hours prior to slaughter. The ovaries and oviducts were collected and weighed. The oviducts were emptied of the contents. The ovaries were examined for follicular development. The diameter of the pubic bones was measured. The eggs were collected daily and an average laying percentage was calculated for each week throughout the study period. The egg weights were recorded after 25 weeks, at which the majority of chickens began to lay in all replicates. The ages at which Koekoek chickens first reached puberty (point of lay), 20\%, 50\%, and greater or equal to $80 \%$ egg productions were recorded. A sample of three eggs weighing between 50 and 55 gram $(\mathrm{g})$ from each replicate for all treatments and less than eight days old was removed and placed in a model SH680 fully automatic digital egg incubator made in South Africa. During the incubation period, the eggs were not turned for the first three days. During days 4-18, egg turning was done three times a day. On day 18, the eggs were removed from trays and placed into the hatching trays until hatching time. The incubator was not disturbed for the last three days of incubation. The chickens were removed from the incubator in the morning after 22 days. The hatching percentage of the eggs was calculated as follows:

Hatching percent $=$ Total number of eggs hatched $x$ $100 /$ Total number of eggs incubated

\section{Statistical analysis}

The data were analyzed using the statistical package for social sciences (SPSS version 17). General Linear Model (GLM) procedure was used to analyze the effect of feed restriction on the reproductive performance of Koekoek chickens.

\section{RESULTS}

\section{Ova and oviducts weights}

The weight of the ova and oviduct in pullets fully fed during the rearing phase (AA and $\mathrm{AR}$ ) was $64.6 \%$ higher than that in the restricted feeding treatments (RA and RR) as stated in table 1 . At 32 weeks of age, Koekoek hens that were fed unrestrictedly during the laying phase (AA and RA) had similar $(\mathrm{p}<0.05)$ ova weights, compared to those that were fed restrictedly during the laying phase (AR and $\mathrm{RR})$. Despite the insignificant differences in ova weight between chickens that were subjected to different feeding levels, the ova weights of restricted feeding chickens (RR) were higher $(p>0.05)$ than those of hens that were in the AA, AR, and RA treatments by $3.4 \%, 2.5 \%$, and $4.7 \%$, respectively. This suggests that restricted feeding during the laying phase stimulated the ova production in Koekoek chickens.

\section{Pubic bones width}

At puberty (18 weeks), fully fed Koekoek chickens had higher $(\mathrm{p}<0.05)$ pubic bone measurements than those under feed restriction (Table 1). On average, the pubic bone widths of chickens that were fully fed were $35.9 \%$ greater $(\mathrm{p}<0.05)$ than the average pubic bone widths of chickens that were subjected to restricted feeding at 18 
weeks of age. During the laying phase (32 weeks), Koekoek chickens that were fully fed during the laying phase had larger $(p<0.05)$ pubic bone widths than those that were fed restrictedly. Koekoek chickens in the RA treatment had a faster pubic bone width growth of $66.9 \%$, followed by chickens in the RR treatment with $66.2 \%$. The lowest in pubic bone width growth was observed in chickens assigned to the AR treatment (40.5\%), while chickens assigned the AA treatment $(51.8 \%)$ ranked the third position between 18 and 32 weeks. These results revealed that restricted feeding during the rearing phase promoted the development of the pubic bones more than full feeding during the same period.

Table 1. Pubic bones, ova, and oviduct growth of Koekoek chickens subjected to different levels of feeding treatments

\begin{tabular}{llccccc}
\hline & & \multicolumn{4}{c}{ Treatments } \\
\hline Age & Variables & AA & AR & RA & RR & S.E \\
\hline \multirow{2}{*}{ 18 weeks } & Pubic bone (mm) & $23.6^{\mathrm{a}}$ & $25.1^{\mathrm{a}}$ & $16.1^{\mathrm{b}}$ & $15.1^{\mathrm{b}}$ & 0.66 \\
& Ova and oviducts (g) & $16.0^{\mathrm{a}}$ & $15.4^{\mathrm{a}}$ & $5.5^{\mathrm{b}}$ & $5.5^{\mathrm{b}}$ & 0.39 \\
\hline \multirow{3}{*}{$\mathbf{3 2}$ weeks } & Pubic bone (mm) & $48.9^{\mathrm{a}}$ & $43.9^{\mathrm{b}}$ & $48.8^{\mathrm{a}}$ & $44.6^{\mathrm{b}}$ & 0.50 \\
& Ova weight (g) & 46.1 & 46.6 & 45.5 & 47.8 & 0.78 \\
& Oviduct weight (g) & 49.1 & 48.1 & 52.0 & 48.0 & 0.80 \\
\hline
\end{tabular}

a,b: Means within a row with no common superscript differ significantly $(\mathrm{p}<0.05)$, S.E: Standard Error. AA: Full feeding during rearing and laying, AR: Full feeding during rearing and restricted during laying, RA: Restricted feeding during rearing and full feeding during laying, RR: Restricted feeding during rearing and laying.

\section{Laying performance}

Koekoek chickens that were subjected to different feeding levels had $(\mathrm{p}<0.05)$ different laying percentages between 18 and 32 weeks of age (Figure 1). Koekoek chickens that were fully fed during the rearing phase (AA and AR) had a significantly $(\mathrm{p}<0.05)$ higher laying percentage between 19 and 21 weeks old, compared to those with restricted feeding (RA and RR). Koekoek chickens that were fully fed throughout the study (AA) had the highest laying percentage, followed by those that were only fed restrictedly during the rearing phase (RA). Koekoek chickens that were only fed restrictedly during the rearing phase (RA) responded positively to the fully fed diet after four weeks. The positive response of RA treatment can be confirmed by the similar laying percentages of chickens that were in the AA and RA treatments from week 25 . On average, chickens that were fully fed during the rearing and laying phase (AA) had higher $(\mathrm{p}<0.05)$ laying percentage.

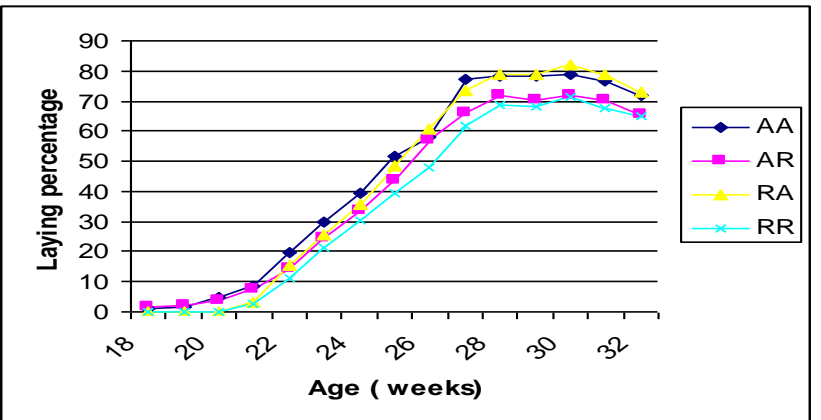

Figure 1. The laying percentage of Koekoek chickens subjected to different feeding levels. AA: Full feeding during rearing and laying, AR: Full feeding during rearing and restricted during laying, RA: Restricted feeding during rearing and full feeding during laying, RR: Restricted during rearing and laying,

\section{Egg weights}

The egg weight of chickens that received different feeding level treatments significantly differed $(\mathrm{p}<0.05)$ throughout the experiment, except at the ages of 27 and 28 weeks (Table 2). At 25 weeks of age, the egg weights of Koekoek chickens that were fed restrictedly for the entire study (RR) were $27.4 \%, 22.6 \%$, and $30.4 \%$ lower $(\mathrm{p}<0.05)$ than the egg weights of chickens that were under the AA, $\mathrm{RA}$, and AR treatments, respectively. On average, chickens that were fully fed during the laying phase (AA and RA) produced eggs of higher weights $(\mathrm{p}<0.05)$ than those that were exposed to restricted feeding ( $A R$ and $R R$ ) during the same phase.

\section{Different egg production stages}

The results on how chickens that were either full-fed or restricted fed performed in terms of age at puberty, $20 \%, 50 \%$, and $80 \%$ egg production are presented in table 3 . The results revealed that restricted feeding affected the number of days to reach different egg production phases.

\section{Hatchability}

Eggs produced by Koekoek chickens subjected to feed restrictions during the laying period (AR and RR) hatched higher $(p<0.05)$ than the eggs from chickens that were unrestrictedly fed during the laying phase (AA and RA) at 28 weeks of age (Table 4). Restricted feeding during the laying phase increased the hatchability of the eggs in Koekoek chickens. The hatching percentages of eggs in the RR treatment were $13.5 \%, 8.9 \%$, and $10.5 \%$ higher $(\mathrm{p}<0.05)$ than in chickens assigned to the AA, AR, 
and RA treatments, respectively. Hatchability increased with age since the hatching percentages of eggs produced from chickens under the AA, AR, RA, and RR treatments increased by $23 \%, 10.9 \%, 21.4 \%$, and $8.9 \%$, respectively. Generally, restricting feed during the laying period could increase hatchability, compared to feeding completely during the laying phase. This meant that the hatching percentage during the laying phase is negatively related to the feed intake and body weight of chickens.

Table 2. Egg weights of Koekoek chickens subjected to different feeding level treatments

\begin{tabular}{|c|c|c|c|c|c|}
\hline Age (Weeks) $\quad$ Treatments & $\mathbf{A A}$ & $\mathbf{A R}$ & $\mathbf{R A}$ & $\mathbf{R R}$ & S.E \\
\hline 26 & $45.5^{\mathrm{a}}$ & $39.7^{b}$ & $45.0^{\mathrm{a}}$ & $39.0^{\mathrm{b}}$ & 0.73 \\
\hline 28 & 46.0 & 45.0 & 47.1 & 46.9 & 0.42 \\
\hline 29 & $48.4^{\mathrm{a}}$ & $46.3^{b}$ & $48.1^{\mathrm{a}}$ & $46.7^{\mathrm{ab}}$ & 0.27 \\
\hline 30 & $47.9^{\mathrm{ab}}$ & $47.3^{\mathrm{a}}$ & $49.2^{\mathrm{b}}$ & $48.1^{\mathrm{ab}}$ & 0.29 \\
\hline Average & $45.6^{\mathrm{a}}$ & $43.5^{\mathrm{b}}$ & $46.7^{\mathrm{a}}$ & $43.1^{\mathrm{b}}$ & 0.22 \\
\hline
\end{tabular}

Table 3. The number of days it takes Koekoek chickens to reach the first oviposition, 20\%, 50\%, and greater or equal to $80 \%$ egg-laying production

\begin{tabular}{|c|c|c|c|c|c|}
\hline $\begin{array}{ll}\text { Variables } & \text { Treatments } \\
\end{array}$ & $\mathbf{A A}$ & $\mathbf{A R}$ & $\mathbf{R A}$ & $\mathbf{R R}$ & S.E \\
\hline Number of days to $1^{\text {st }}$ oviposition & $150.1^{\mathrm{a}}$ & $152.4^{\mathrm{a}}$ & $159.0^{\mathrm{b}}$ & $159.8^{\mathrm{b}}$ & 0.61 \\
\hline Number of days to $20 \%$ production & $163.5^{\mathrm{a}}$ & $164.1^{\mathrm{b}}$ & $166.9^{\mathrm{ab}}$ & $168.3^{\mathrm{b}}$ & 0.79 \\
\hline Number of days to $50 \%$ production & 174.1 & 172.8 & 175.0 & 176.1 & 0.79 \\
\hline Number of days to $\geq 80 \%$ production & $191.7^{\mathrm{a}}$ & $190.7^{\mathrm{a}}$ & $189.1^{\mathrm{a}}$ & $199.4^{\mathrm{b}}$ & 1.19 \\
\hline
\end{tabular}

a, b: Means within a row with no common superscripts differ significantly $(\mathrm{p}<0.05)$. S.E: standard error; AA: Full feeding during rearing and laying, AR: Full feeding during rearing and restricted during laying, RA: Restricted feeding during rearing and full feeding during laying, RR: Restricted feeding during rearing and laying

Table 4. Egg hatching percentage of Koekoek chickens subjected to different feeding levels

\begin{tabular}{|c|c|c|c|c|}
\hline $\begin{array}{ll}\text { Age }(\text { Weeks }) & \text { Treatments } \\
\end{array}$ & $\mathbf{A A}$ & $\mathbf{A R}$ & RA & RR \\
\hline 28 & $62.1^{\mathrm{a}}$ & $75.7^{b}$ & $65.7^{\mathrm{a}}$ & $85.0^{\mathrm{b}}$ \\
\hline 30 & $75.0^{\mathrm{a}}$ & $89.3^{b}$ & $78.6^{\mathrm{a}}$ & $92.5^{\mathrm{b}}$ \\
\hline 32 & $80.7^{\mathrm{a}}$ & $85.0^{\mathrm{a}}$ & $83.6^{\mathrm{a}}$ & $93.3^{\mathrm{b}}$ \\
\hline Average & $72.6^{\mathrm{a}}$ & $83.3^{\mathrm{b}}$ & $76.0^{\mathrm{a}}$ & $90.3^{\mathrm{c}}$ \\
\hline
\end{tabular}

$\overline{a, b, c:}$ Means within a row with no common superscript differ significantly $(\mathrm{p}<0.05)$. AA: Full feeding during rearing and laying, AR: Full feeding during rearing and restricted during laying, RA: Restricted feeding during rearing and full feeding during laying, RR: Restricted feeding during rearing and laying, S.E: Standard Error

\section{DISCUSSION}

Concerning the ova weights, the results of the present study agreed with the findings of Crounch et al. (2002), who stated that the maturing ova were heavier in turkeys that were fed restrictedly during the rearing period than in those that were fed ad libitum in the rearing phase. Simeneh (2019) also found that limited feed at the rearing phase hindered the development of the oviducts. On the contrary, Renema et al. (1999) pointed out that restricted feeding chickens were 38\% lower than ad libitum feeding chickens in terms of the ovary weights. In addition, Robinson et al. (2007) reported that the ovary weights were influenced by body weight and possibly by fat content. Yildiz et al. (2006) also suggested that ad libitumfed chickens showed accelerated development of oviducts.

The findings of previous researchers indicated similar oviduct weights between chickens that were 
subjected to different feeding regimes at sexual maturity (Tesfaye et al., 2009; Renema et al., 2007; Renema et al., 1999). Yildiz et al. (2006) also suggested that restricting feed during the rearing period significantly delayed oviduct development. Moreover, Cassy et al. (2004) and Renema et al. (2007) confirmed that chickens that were exposed to feeding restrictions during the growing period had a decreased number of large yellow follicles at first oviposition.

Crounch et al. (2002) also found that the total egg production was higher in chickens that were fully fed during the laying period. The findings of the present study tally with the results of Oyedeji et al. (2007) who reported that the egg weight was significantly higher in hens that were fed ad libitum, compared to those that were restricted.

Concerning egg weight, Moreira et al. (2012) also stated that it was not affected by the dietary restriction. Evrim and Kaya (2014) also found that early feed restriction did not affect the average egg weights in quails. On the other hand, Miles and Jacqueline (2000) showed that a feed restriction program would result in a slight decrease in egg size, which was less significant when the majority of eggs were in large category, which was in line with the results of the present study showing the effect after 30 weeks.

It was found that the reduction of egg production in layers that were restrictedly fed throughout the study (RR), the last group to reach one of the egg production stages, was consistent with the obtained results of a study conducted by Ezieshi et al. (2003). In a study on quails, Evrim and Kaya (2014) emphasized that feed restriction delayed the onset of laying as was observed in the findings of the present study since chickens treated with feed restrictions during the rearing phase ( $R A$ and $R R$ ) experienced delayed sexual maturity. In addition, Onagbesan et al. (2006) stated that chickens with restricted feeding would take a longer period to reach maximum egg production than chickens that were fully fed. Crounch et al. (2002) also stated that turkeys that were fed restrictedly at the rearing period (3-16 weeks) had a significantly higher egg production than those that were fully fed during the growing period.

In support of these results, Simeneh (2019) stated that early feed restriction reduced overall embryonic mortality. Crounch et al. (2002) also indicated that turkeys that were shifted from restricted feeding during the rearing phase to ad libitum feeding during the laying phase had a significantly higher embryonic mortality, and thus a lower hatching percentage compared to the other treatments.
Evrim and Kaya (2014) also reported that mortality in fully fed quails increased by $56 \%$.

\section{CONCLUSION}

Full feeding during the rearing phase resulted in reduced pubic bones, ova, and oviducts development, delayed oviposition, and $20 \%$ egg production. Full feeding in the laying phase led to a higher laying percentage and egg weights despite the fully fed or restrictedly fed diets of chickens during the rearing phase. Therefore, Koekoek chickens should only be fed restrictedly during the rearing phase since their performance in terms of laying percentage, egg weight, and early peak egg production did not differ from those that were fully fed throughout the study. In the case where a farmer is interested in hatching, a feed restriction would be an ideal practice in order to maximize egg hatchability.

\section{DECLARATIONS}

\section{Acknowledgements}

The authors would like to thank the Department of Animal Science of the National University of Lesotho for providing facilities used in the current study.

\section{Competing interests}

The authors declare that they have no conflict of interest.

\section{Author's contribution}

Setsumi M. Molapo and Edward Webb developed the concept, analysed data and wrote the manuscript. Motselisi A. Mahlehla and Paseka Kompi assisted in data collection while Thato Chabeli designed the graphical abstract. All authors reviewed and confirmed the manuscript before submission.

\section{REFERENCES}

Adegbenro M, Ajidara SA, Modupe G, and Onibi EG (2020). Performance and Egg Qualities of Isa-Brown Layers Fed Different Quantities of Feed at Varying Feeding Frequencies. Turkish Journal of Agriculture - Food Science and Technology, 8(4): 864-872. DOI: https://doi.org/10.24925/turjaf.v8i4.864-872.3014

Cassy S, Metayer S, Crochet S, Rideau N, Collin A, and Tesserand S (2004). Leptin receptor in the chicken ovary: Potential involvement in ovarian dysfunction of ad libitumfed broiler breeder hens. Reproductive Biology and

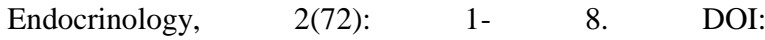
https://doi.org/10.1186/1477-7827-2-72 
Crounch AN, Grimes JL, Christensen VL, and Kruegert KK (2002). Effect of physical feed restriction during rearing on large white turkey breeder hens: 2. Reproductive performance. Poultry Science, 81: 16-22. DOI: https://doi.org/10.1093/ps/81.1.16

Evrim DF, and Kaya M (2014). Effects of early feed restriction on some performance and reproductive parameters in japanese quail). International Journal of Poultry Science, 13(6): 323328. DOI: https://doi.org/ 10.3923/ijps.2014.323.328

Ezieshi VE, Nworu MJ, Bandele FO, Suleman RO, Ojurongbe $\mathrm{BC}$, and Olomu JM (2003). Laying hen productivity in the tropics as affected by stage of egg production, feed restriction, stocking density and time of day. Archivos de Zootecnia, 52(200): 475-482. Available at: http://www.redalyc.org/articulo.oa?id=49520006

Melnychuk VL, Kirby JD, Kirby YK, Emmerson DA, and Anthony NB (2004). Effect of strain, feed allocation program, and age at photo stimulation on reproductive development and carcass characteristics of broiler breeder hens. Poultry Science, 83(11): 1861-1867. DOI: https://doi.org/10.1093/ps/83.11.1861

Miles RD, and Jacqueline PJ (2000). Feeding the commercial eggtype laying hen. factsheet ps049" department of dairy and poultry science. Florida cooperative extension service. University of Florida, Pp. 1-4. Available at: http://edis.ifas.ufl.edu/

Moreira RF, Freitas ER, Sucupira FS, Diógenes ALF, Abe MS, and Araújo FWS (2012). Effect of feed restriction with voluntary hay intake on the performance and quality of laying hen eggs. Acta Scientiarum Animal Sciences, 34(2): 149-154.

DOI: https://doi.org/10.4025/actascianimsci.v34i2.12451

Onagbesan OM, Metayer S, Tona K, Williams J, Decuypere E, and Bruggeman V ( 2006). Effects of genotype and feed allowance on plasma luteinizing hormones, Follicle Stimulating hormones, progesterones, estradiol levels, follicle differentiation, and egg production rates of broiler breeder hens. Poultry Science, 85(7): 1245-1258. DOI: https://doi.org/10.1093/ps/85.7.1245
Oyedeji JO, Orheruata AM, and Omatsuli M (2007). Effects of feed rationing on the laying performance of 40 weeks in lay hens. Journal of Food, Agriculture and Environment, 5: 301-303. DOI: https://doi.org/10.1234/4.2007.1205

Renema RA, Robinson FE, and Zuidhof MJ (2007). Reproductive efficiency and metabolism of female broiler breeders as affected by genotype, feed allocation, and age at photo stimulation. 2. Sexual maturation. Poultry Science, 86(10): 2267-2277. DOI: https://doi.org/10.1093/ps/86.10.2267

Renema RA, Robinson FE, Proudman JA, Newcombe M, and Mckay RA (1999). Effect of body weight and feed allocation during sexual maturation in broiler breeder. 2 . Ovarian morphology plasma hormone profiles. Poultry Science, 78(5): 629-639. DOI: https://doi.org/10.1093/ps/78.5.629

Robinson FE, Zuidhof MJ, and Renema RA (2007). The reproductive efficiency and metabolism of female broiler breeders as affected by genotype feed allocation and age at photo stimulation. 1. Pullet growth and developments. Poultry Science, 86(10):2256-2266. DOI: https://doi.org/10.1093/ps/86.10.2256

Salih R, Tesfaye E, Tamir B, and Singh H (2016). Effects of Feed Restriction on Production Performance and Carcass Characteristics of Koekoek Chickens in Ethiopia. Poultry science Journal, 4 (1): 55-61. Available at: http://psj.gau.ac.ir

Simeneh G (2019). Review on the effect of feed and feeding on chicken performance. Animal Husbandry Dairy and Veterinary Science, 3: 1-4. DOI: https://doi.org/10.15761/AHDVS.1000171

Tesfaye E, Tamir B, Haile A, and Dessie T (2009). Effects of feed restriction on production and reproductive performance of Rhode island red pullets, 4(7). Available at: http://www.academicjournals.org/AJAR

Yildiz H, Yilmaz B, Arican I, Petek M, and Bahadir A (2006). Effects of cage systems and feeding time on the morphological structure of female genital organs in Pharaoh Quails (Coturnix coturnix pharaoh). Veterinarski Archive, 76(5): 381-389. Available at: https://hrcak.srce.hr/file/8254 